\title{
Maternal birth preparedness and complication readiness in the Greater Accra region of Ghana: a cross-sectional study of two urban health facilities
}

Cynthia Klobodu ${ }^{1}$, Brandy-Joe Milliron ${ }^{2 *}$ (D, Kofi Agyabeng ${ }^{3}$, Patricia Akweongo ${ }^{1}$ and Augustine Adomah-Afari ${ }^{1}$

\begin{abstract}
Background: High maternal mortality ratios remain a critical public health concern in Ghana. Birth preparedness and complication readiness (BP/CR), which is a component of focused antenatal care, is a safe motherhood strategy intended to promote skilled birth attendance by helping women and their families plan for pregnancy and childbirth, thereby reducing maternal mortality. The objective of this study was to determine the level of BP/CR and to assess factors associated with maternal BP/CR in the Greater Accra Region of Ghana.

Method: A cross sectional descriptive quantitative study was carried out among 300 postnatal women attending the Adabraka Polyclinic and the Greater Accra Regional Hospital both within Accra, the capital city of Ghana. Data were collected with a structured questionnaire which assessed socio-demographic, health facility/provider and social support factors and their associations with BP/CR. Levels of BP/CR were assessed using validated tools. Data from 300 women were analyzed using STATA version 15.0. Logistic regression analysis was conducted to establish associations between BP/CR and socio-demographic, health facility/ provider and social support factors.

Results: Approximately 234 (78\%) of the women were birth prepared. Strong predictors of BP/CR included having $\geq 4$ antenatal clinic visits (aOR 2.63; 95\% Cl 1.03-6.73), being employed (aOR 4.07; 95\% Cl 1.49-11.11) and belonging to maternal health promoting clubs or groups during the antenatal period (aOR 3.00; $95 \% \mathrm{Cl}$ 1.07-8.40) .

Conclusion: BP/CR is generally high among the study population. Predictors of BP/CR are multifactorial and found to cut across all aspects assessed in the study. Therefore, the creation of a BP/CR tool is recommended to routinely monitor trends in maternal birth preparedness in antenatal clinics. This may help to sustain and improve current levels and indicators of BP/CR.
\end{abstract}

Keywords: Birth preparedness and complication readiness, Skilled birth attendance, Safe motherhood initiative, Antenatal clinic, Postnatal clinic

\footnotetext{
* Correspondence: bm645@drexel.edu

${ }^{2}$ Department of Nutrition Sciences, Centre for Family Intervention Science,

College of Nursing and Health Professions, Drexel University, 1601 Cherry

Street. Suite 383, Philadelphia, PA 19102, USA

Full list of author information is available at the end of the article
}

(c) The Author(s). 2020 Open Access This article is licensed under a Creative Commons Attribution 4.0 International License, which permits use, sharing, adaptation, distribution and reproduction in any medium or format, as long as you give appropriate credit to the original author(s) and the source, provide a link to the Creative Commons licence, and indicate if changes were made. The images or other third party material in this article are included in the article's Creative Commons. licence, unless indicated otherwise in a credit line to the material. If material is not included in the article's Creative Commons licence and your intended use is not permitted by statutory regulation or exceeds the permitted use, you will need to obtain permission directly from the copyright holder. To view a copy of this licence, visit http://creativecommons.org/licenses/by/4.0/. The Creative Commons Public Domain Dedication waiver (http://creativecommons.org/publicdomain/zero/1.0/) applies to the data made available in this article, unless otherwise stated in a credit line to the data. 


\section{Background}

Although Sustainable Development Goal 3 (SDG3) has a target of reducing the maternal mortality ratio (MMR) to less than 70 per 100,000 live births in 2030, the burden in Ghana remains high with a MMR of 310 per 100, 000 live births [1]. This goal may not be reached with the annual reduction rate of $2.7 \%$ as opposed to the required estimate of $7.5 \%[1,2]$.

Data from the Ghana Health Service (GHS) showed that the highest number of maternal deaths was reported in the Greater Accra Region in 2016 with 130 deaths, closely followed by the Eastern Region with a little under 100 deaths [3]. A high proportion of direct maternal deaths was due to obstetric hemorrhage, followed by hypertensive disorders of pregnancy [3].

Skilled birth attendance is one of the most important factors for reducing maternal mortality and birth preparedness and complication readiness $(\mathrm{BP} / \mathrm{CR})$ is an approach to promote this $[4,5]$. The prevalence of skilled birth attendance was recorded as $56.2 \%$ nationwide and 59.4\% for the Greater Accra Region in 2016 according to GHS whereas the Demographic and Health Survey (DHS) reported $73.7 \%$ nationwide and $92.5 \%$ for the Greater Accra Region in 2014 [3, 5]. GHS attributes its lower numbers to lack of a centralized data collection system to capture births from private facilities and maternity homes [3].

The World Health Organisation (WHO) recommends that every pregnant woman should have a written $\mathrm{BP} /$ CR plan, discussed with a skilled birth attendant during every antenatal visit or at least one month prior to birth [6]. Antenatal clinics in Ghana are run by midwives, nurses and doctors and follow WHO's focused antenatal care (FANC) approach [7]. FANC is a continuum of care which emphasizes evidence-based interventions including $\mathrm{BP} / \mathrm{CR}$ for all women, in addition to providing care and support for women and their families [8].

Levels of BP/CR vary across the literature and are generally low [9]. Socio-demographic characteristics, including age, parity and education as well as socio-economic factors, such as income, have been shown to influence $\mathrm{BP} / \mathrm{CR}$ across different socio-cultural settings. Social support factors, such as spousal, family and community support, also appear to influence BP/CR. Furthermore, definitions of $B P / C R$ vary in the literature, which may account for inconsistencies between different studies [10]. The WHO's BP/CR plan involves identifying: 1. place of birth; 2 . preferred skilled birth attendant; 3 . location of an appropriate facility for birth in close proximity; 4. funds for any expenses related to birth and emergencies; 5. a labor and birth companion; 6. care support at home while the woman is away; 7 . transport to a health facility for birth 8 . transport in case of obstetric emergencies and 9. compatible blood donors when needed [6]. The Johns Hopkins Program for International Education in Gynaecology and Obstetrics (JHPIEGO)'s package provides well described roles for all stakeholders, including community members and policy makers, thereby making the plan more comprehensive [11].

Certain countries, such as Nepal, have instituted birth preparedness cards, also known as 'key chains,' with messages on birth preparedness [12]. Tanzania, Ethiopia, Uganda, Eritrea and Kenya included home visits by volunteers to educate families on BP/CR; training of health workers to provide information and support on $\mathrm{BP} / \mathrm{CR}$; provision of visual aids and educational materials on $\mathrm{BP} /$ $\mathrm{CR}$; and community surveillance systems for pregnancies, which are all periodically assessed [10]. In Rwanda, Community Health Workers (CHWs) iterate BP/CR messages through mobile technology in the form of SMS alerts, in addition to home visits and community meetings [13].

$\mathrm{BP} / \mathrm{CR}$, however, is not routinely assessed in Ghana and researchers who have assessed $\mathrm{BP} / \mathrm{CR}$ have not used consistent instruments. Little information on $\mathrm{BP} / \mathrm{CR}$ is known in urban areas as most research has been conducted in rural Ghana [14-16]. This study intends to add knowledge on BP/CR using a systematic method. The objective is to determine levels of $\mathrm{BP} / \mathrm{CR}$ and to assess factors associated with $\mathrm{BP} / \mathrm{CR}$ in the Greater Accra Region of Ghana.

\section{Methods}

\section{Study design, setting and population}

A facility-based cross-sectional study was conducted in Adabraka Polyclinic, a primary care facility, and Greater Accra Regional Hospital a referral facility in Osu Klottey Sub-Metro (both facilities now lie within the Korle Klottey Municipal Assembly) of the Accra Metropolitan Assembly (AMA) between March 2019 and May 2019. The population of Osu Klottey Sub-Metro was 151,712 with 36,411 women of reproductive age and an expected number of pregnancies of 6068 in 2017. The Accra metropolis was chosen because it houses the capital city of the Greater Accra Region and Ghana.

\section{Sample size and sampling procedure}

Sample size was determined using the single population proportion formula. A BP/CR level of $23.0 \%$ was considered from a previous study [15]. A sample size of 300 women was calculated by using $95 \%$ level of significance, 0.05 margin of error and a $10 \%$ non-response rate. A stratified random probability sampling method was used to recruit women from both facilities. Women were recruited to participate if they were between 18 and 49 years old, had given birth within the last six weeks, and 
attended postnatal clinics (PNC) in any of the two facilities.

Using PNC records of both facilities, Adabraka Polyclinic was estimated to have an average attendance of 50 women per week and a five weeks study period estimated an average of 250 women. Greater Accra Regional Hospital had an average attendance of 100 women per week and an estimated average of 500 women for the five weeks study duration. The required sample size was then proportionately allocated to the two health facilities with Adabraka Polyclinic having 100 women and Greater Accra Regional Hospital 200 women. Recruitement was done by mouth and through distribution of flyers in both facilities. Simple random samping was subsequently used in both facilities to enroll participants. A list of PNC attendees was entered in Microsoft Excel, unique numbers were assigned to them and the total number of women per day randomly chosen.

\section{Data collection}

A structured questionnaire with four sections was designed for the purposes of this study. Section A included personal and sociodemographic characteristics, such as age, parity, marital status, income, religion, employment status and wealth index. Section B included data on facility and social support factors, such as proximity to the clinic, antenatal clinic (ANC) attendance during last pregnancy, place of birth (as a proxy for skilled birth attendance), and maternal health promoting clubs or groups membership. Section $C$ included information regarding $B P / C R$ using the Maternal and Child Health Records (MCHR) book of 2018 [17]. This book was developed by the Japanese International Cooperation Agency (JICA) in collaboration with the Ministry of Health and GHS in accordance with WHO's recommendations on home-based records for maternal and newborn care, serving as a standard instruction guide and records' book for women and health facilities across the country [18]. The questionnaire was either selfor interviewer-administered, depending on the educational background of the women.

\section{Operational definitions}

Women were classified as birth prepared if they reported at least four out of seven factors in the MCHR book [17]. This scoring system has been employed by several other studies $[2,14,15]$. Those factors are: 1 ) making arrangements for transport; 2) making arrangements for helpers to take care at home while women are away during birth; 3) deciding where to give birth; 4) saving money for care and transport; 5) having a valid health insurance; 6) identifying a blood donor; and 7) having knowledge of 11 danger signs of pregnancy. These signs include: headache; swollen feet, arms and face; convulsive fits; breakage of bag of water before expected date of delivery (EDD); dizziness, difficulty in breathing and rapid heart beating; increase in body temperature; increase or decrease or no movement of baby; smelly or greenish water from birth canal; persistent vomiting; severe abdominal pain; and bleeding [17]. A score of ' 1 (= yes)' was awarded for knowing all danger signs and a score of ' 0 (= No)' for missing one danger sign. The decision to score +1 point if the respondent knows all 11 danger signs is based on WHO's recommendations as stated in the Counselling for Maternal and Newborn Health care handbook [19].

Due to uncertainties and bias in income reporting, wealth index was used as a proxy indicator. The assetbased wealth index provides a composite quantification of participants' cumulative standard of living, using information gathered about ownership of certain selected assets. The Equity tool abridged wealth index for Ghana [20], comprising of a 13 household item list, was adapted to collect this data.

Using principal component analysis, an index was computed to put participants on a continuous scale of relative riches. Based on that, participants were then categorized into five wealth quintiles: the first 20th percentile group, representing the relatively poorest quintile of the participants and 5th quintile, representing the relatively richest participants.

\section{Data analysis}

Descriptive statistics on categorical variables were reported in terms of frequencies and percentages. Bar charts were also used for pictorial illustrations. A multiple binary logistic regression model was used in determining predictors of $\mathrm{BP} / \mathrm{CR}$ among women who recently had given birth. Results of the logistic regression model are reported as odds ratios with $95 \%$ confidence intervals. All statistical tests were done at $5 \%$ significance level.

\section{Results}

Socio-demographic characteristics of respondents

Out of the 300 included women 153 (51\%) were $\leq 29$ years, $230(76.7 \%)$ were married or cohabiting and 225 (75\%) were employed; 199 (66.3\%) had between one and two children and 287 (95.6\%) had some form of education with only 11 (3.7\%) having no formal education (Table 1).

\section{Health facility/provider and social support factors on} $\mathrm{BP} / \mathrm{CR}$

Over half $172(57.3 \%)$ of the women spent $>1 \mathrm{~h}$ to get to the nearest health facility. One hundred and eighty-four 
Table 1 Socio-demographic characteristics of women attending postnatal care

\begin{tabular}{|c|c|c|}
\hline Variable & Frequency & Percentage \\
\hline \multicolumn{3}{|l|}{ Age group (Years) } \\
\hline$\leq 29$ & 153 & 51.0 \\
\hline $30-39$ & 114 & 38.0 \\
\hline $40-49$ & 31 & 10.3 \\
\hline Missing data & 2 & 0.7 \\
\hline \multicolumn{3}{|l|}{ Marital Status } \\
\hline Married/cohabiting & 230 & 76.7 \\
\hline Single & 62 & 20.7 \\
\hline Missing data & 8 & 2.7 \\
\hline \multicolumn{3}{|l|}{ Parity } \\
\hline $1-2$ children & 199 & 66.3 \\
\hline More than 3 children & 94 & 31.3 \\
\hline Missing data & 7 & 2.3 \\
\hline \multicolumn{3}{|l|}{ Religion } \\
\hline Christian & 208 & 69.3 \\
\hline Non-Christian & 89 & 29.7 \\
\hline Missing data & 3 & 1.0 \\
\hline \multicolumn{3}{|l|}{ Educational Level } \\
\hline No formal education & 11 & 3.7 \\
\hline Primary & 88 & 29.3 \\
\hline Secondary & 82 & 27.3 \\
\hline Tertiary & 117 & 39.0 \\
\hline Missing data & 2 & 0.7 \\
\hline \multicolumn{3}{|l|}{ Employment status } \\
\hline Unemployed & 74 & 24.7 \\
\hline Employed & 225 & 75.0 \\
\hline Missing data & 1 & 0.3 \\
\hline \multicolumn{3}{|l|}{ Wealth Index } \\
\hline Poorest & 41 & 13.7 \\
\hline Poorer & 41 & 13.7 \\
\hline Middle & 42 & 14.0 \\
\hline Rich & 40 & 13.3 \\
\hline Richer & 41 & 13.7 \\
\hline Missing data & 95 & 31.7 \\
\hline \multicolumn{3}{|l|}{ Health Facility } \\
\hline APC & 100 & 33.3 \\
\hline GARH & 200 & 66.7 \\
\hline
\end{tabular}

APC Adabraka Polyclinic, GARH Greater Accra Regional Hospital

(61.3\%) reported more than four antenatal visits during their last pregnancy (Table 2). About 295 (98.3\%) reported that they had given birth in a health facility which was used as a proxy for skilled birth attendance, while only five women (1.7\%) gave birth at home. The majority (281; 93.7\%) of the respondents from both facilities
Table 2 Health facility/provider and social support factors on birth preparedness

\begin{tabular}{|c|c|c|}
\hline Variable & Number & Percentage \\
\hline \multicolumn{3}{|c|}{ Average travel time to nearest health facility } \\
\hline$<1 \mathrm{~h}$ & 172 & 57.3 \\
\hline$\geq 1 \mathrm{~h}$ & 127 & 42.3 \\
\hline Missing data & 1 & 0.3 \\
\hline \multicolumn{3}{|l|}{ ANC attendance for last pregnancy } \\
\hline$<4$ visits & 116 & 38.7 \\
\hline$\geq 4$ visits & 184 & 61.3 \\
\hline \multicolumn{3}{|l|}{ Place of birth } \\
\hline Health Facility & 295 & 98.3 \\
\hline Home & 5 & 1.7 \\
\hline \multicolumn{3}{|l|}{ Social support } \\
\hline received support & 281 & 93.7 \\
\hline no support received & 19 & 6.3 \\
\hline \multicolumn{3}{|c|}{ Maternal health promoting club/ group membership } \\
\hline belonged to clubs/groups & 123 & 41.0 \\
\hline did not belong to club/groups & 177 & 59.0 \\
\hline
\end{tabular}

ANC Antenatal Clinic

reported having had some form of emotional and financial support during their last pregnancy. However, less than half $(123 ; 41 \%)$ reported belonging to maternal health promoting groups or clubs during their last pregnancy (Table 2).

\section{Level and aspects of $\mathrm{BP} / \mathrm{CR}$}

Of the 300 respondents, 234 (78\%) were prepared for birth. A valid health insurance was held by 263 (90\%), whereas only 148 (51\%) had made arrangements for a blood donor (Fig. 1i). Two hundred and fifty-two (85\%) decided on the place of birth and 248 (85\%) also saved money for birth. Transport to the health facility was arranged by 187 (64\%) and 202 (69\%) arranged assistance to take care of the home during their absence. Only 171 (58\%) were able to correctly identify all 11 danger signs in pregnancy (Fig. 1i). There were very significant differences in the proportions of the seven aspects of $\mathrm{BP} / \mathrm{CR}$ between those who were considerd to be prepared and those not prepared (Fig. 1ii).

\section{Predictors of BP/CR among women who recently gave birth}

From the multiple binary logistic regression model, ANC attendance for last pregnancy, employment status and maternal health promoting club or group membership were identified to be statistically significantl predictors of $\mathrm{BP} / \mathrm{CR}(p<0.05)$. Odds of being birth prepared was 2.6 times higher among women who had $\geq 4$ ANC visits compared to those with $<4$ ANC visits (aOR 2.63; 

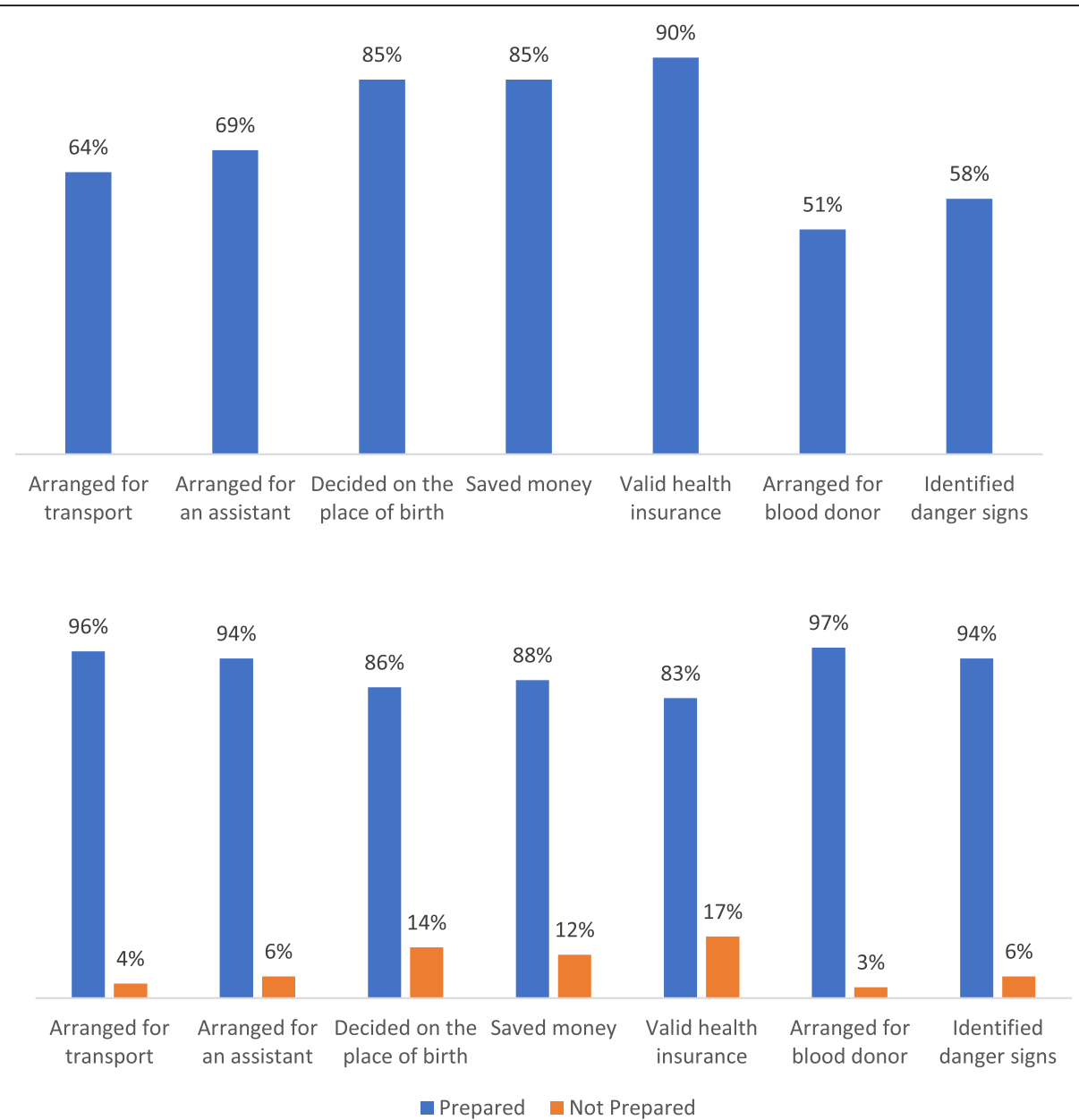

Fig. 1 i: Aspects of BP/CR that were planned. Descriptive results presented as a percentage of participants prepared for each category, $n=300$. Figure 1 ii: Aspects of BP/CR that were planned. Descriptive results presented as percentage of participants prepared for each category $(n=300)$, who were either birth prepared or not birth prepared

95\%CI 1.03-6.73). With regards to employment status, mothers who were employed had $\geq 4$ times higher odds of being birth prepared compared to unemployed women (aOR 4.07; 95\% CI 1.49-11.11). Odds of being birth prepared among mothers belonging to maternal health promoting clubs or groups was 3 times higher compared to mothers who did not (aOR 3.00; 95\% CI 1.07-8.40) (Table 3).

\section{Discussion}

Levels of BP/CR among women who recently delivered

We found $78 \%$ of the women to be birthprepared. This is consistent with a large community-based study in the Osogbo Metropolis of Southwest Nigeria, which found that $82.1 \%$ were birth prepared [21] and a study in an urban hospital in Hyderabad in India which found a 71.5\% BP/CR level [22]. Many community and facility-based studies, however, have much lower BP/CR levels. For example, a multisite health facility based study in Kassena Nankana District and a community-based study in Sisala East District both of Northern Ghana reported that 16.2 and $23 \%$ of the women were birth prepared [14, 15]. A similar study in Tamale Teaching Hospital in the Northern Region of Ghana found BP/CR levels of $43.7 \%$, while a mixed health facility and community-based study among teenage mothers in the Ledzorkuku Krowor Municipal Assembly in the Greater Accra Region reported 40.0\% to be more birthprepared [16, 23]. Equally low rates have been reported in other countries with $20 \% \mathrm{BP} /$ $\mathrm{CR}$ in a health facility-based study in Tharaka Nithi County in Kenya, $41.1 \%$ in Mizan-Tepi University Hospital in Southwest Ethiopia and $47.8 \%$ in a slumbased study with a functional maternal and child health program in Indore in India [24-26]. Discrepancies between our findings and these studies could be explained by socioeconomic factors. The studies in Kassena Nankana District, Sisala East District and 
Table 3 Predictors of BP/CR among women who recently gave birth

\begin{tabular}{|c|c|c|c|c|c|}
\hline \multirow{3}{*}{ Age Group } & \multicolumn{2}{|c|}{ Unadjusted } & \multicolumn{3}{|c|}{ Adjusted } \\
\hline & \multirow[t]{2}{*}{ cOR } & \multirow[t]{2}{*}{$95 \% \mathrm{Cl}$} & \multirow[t]{2}{*}{$\mathrm{aOR}$} & \multicolumn{2}{|l|}{$95 \% \mathrm{Cl}$} \\
\hline & & & & & \\
\hline $18-28$ & 1.00 & & 1.00 & & \\
\hline 29-39 & 3.33 & $1.79-6.21$ & 2.15 & $0.79-5.91$ & \\
\hline $40-49$ & 1.67 & $0.66-4.21$ & 0.95 & $0.19-4.8$ & \\
\hline \multicolumn{6}{|l|}{ Marital Status } \\
\hline Married/Cohabiting & 1.00 & & 1.00 & & \\
\hline Single/Divorced/Widowed & 0.58 & $0.31-1.09$ & 1.09 & $0.33-3.64$ & \\
\hline \multicolumn{6}{|l|}{ Parity } \\
\hline$<3$ & 1.00 & & 1.00 & & \\
\hline$\geq 3$ & 2.54 & $1.29-5.03$ & 2.21 & $0.61-8.02$ & \\
\hline \multicolumn{6}{|l|}{ Religion } \\
\hline Christian & 1.00 & & 1.00 & & \\
\hline Non-Christian & 0.79 & $0.44-1.43$ & 1.60 & $0.55-4.68$ & \\
\hline \multicolumn{6}{|l|}{ Wealth Index } \\
\hline Poorest & 1.00 & & 1.00 & & \\
\hline Poorer & 2.01 & $0.7-5.78$ & 0.96 & $0.25-3.69$ & \\
\hline Middle & 1.52 & $0.56-4.12$ & 0.72 & $0.18-2.81$ & \\
\hline Rich & 2.34 & $0.78-7.03$ & 3.67 & $0.68-19.85$ & \\
\hline Richer & 2.98 & $0.94-9.43$ & 1.63 & $0.34-7.81$ & \\
\hline \multicolumn{6}{|c|}{ Average Travel Time to Nearest Health Facility } \\
\hline$<1 \mathrm{~h}$ & 1.00 & & 1.00 & & \\
\hline$\geq 1 \mathrm{~h}$ & 1.14 & $0.65-1.99$ & 1.69 & $0.64-4.43$ & \\
\hline \multicolumn{6}{|l|}{ ANC Attendance for last pregnancy } \\
\hline$<4$ Visit & 1.00 & & 1.00 & & \\
\hline$\geq 4$ Visits & 3.48 & $1.97-6.14$ & 2.63 & $1.03-6.73$ & \\
\hline \multicolumn{6}{|l|}{ Social Support } \\
\hline No support received & 1.00 & & 1.00 & & \\
\hline Received support & 7.21 & $2.71-19.17$ & 4.24 & $0.87-20.55$ & \\
\hline \multicolumn{6}{|l|}{ Employment Status } \\
\hline Unemployed & 1.00 & & 1.00 & & \\
\hline Employed & 4.68 & $2.6-8.44$ & 4.07 & $1.49-11.11$ & \\
\hline \multicolumn{6}{|l|}{ Educational Level } \\
\hline No formal education & 0.22 & $0.06-0.79$ & 0.04 & $0.00-0.78$ & \\
\hline Primary & 0.55 & $0.27-1.09$ & 1.80 & $0.45-7.22$ & \\
\hline Secondary & 0.56 & $0.28-1.15$ & 0.94 & $0.33-2.67$ & \\
\hline Tertiary & 1.00 & & 1.00 & & \\
\hline \multicolumn{6}{|c|}{ Maternal Health Promoting Club/ Group Membership } \\
\hline Did not belong to club/groups & 1.00 & & 1.00 & & \\
\hline Belonged to clubs/groups & 1.52 & $0.86-2.69$ & & 3.00 & $1.07-8.4$ \\
\hline
\end{tabular}

CI Confidence interval, cOR Crude odds ratio, aOR Adjusted odds ratio

Tamale Teaching Hospital were all conducted in northern Ghana, which is known to have wide socioeconomic developmental gaps as compared with the southern part of the country [27]. In addition, the study among teenage mothers, although conducted in southern Ghana, had low levels of BP/CR because the 
mothers may not have been adequately empowered due to their status in society [23].

In our study, some aspects of $\mathrm{BP} / \mathrm{CR}$ were more planned than others. The most prepared for was having a valid health insurance (90.4\%), whereas the least was arranging for a blood donor (50.4\%). Ghana's National Health Insurance Scheme offers free maternal care and coverage involves four antenatal visits as well as the costs of skilled birth attendance [28]. This could have contributed to the high proportions of $\mathrm{BP} / \mathrm{CR}$ in this aspect, although there may be some form of payments made during birth in health facilities. Similar to our findings, a study in Southwest Nigeria found that arranging for a blood donor was the least action women had undertaken towards BP/CR [21]. Generally, sociocultural perceptions concerning blood donation and reception in Ghana hinder some people deciding to give or receive blood [29] despite high levels of iron deficiency anaemia, which is associated with post-partum hemorrhage especially amongst women of childbearing age [30]. The government must therefore work to improve national blood banking systems and promote blood donation efforts. Blood transfusion should also be discussed with pregnant women early on in the pregnancy to address misconceptions and alternative treatment methods [31].

Our study assessed knowledge on all 11 danger signs of pregnancy in the MCHR book according to WHO's recommendations, and found only $58 \%$ of the women to be knowledgeable of all 11 signs. The leading causes of maternal mortality world wide include hemorrhage, hypertensive disorders and sepsis, and so it's important for pregnant mothers to have adequate knowledge concerning signs associated with these conditions [32]. Studies show that women commonly miss danger signs associated with pre-eclampsia and eclampsia due to inadequate emphasis on all danger signs during antenatal visits [33]. However, certain danger signs may also be more clinically relevant than others depending on the stage of the pregnancy [33]. Therefore, more research is needed in this area to help prioritize danger signs during antenatal education. Having adequate knowledge of danger signs empowers women to identify and seek help early thereby improving maternal and fetal outcomes [34].

\section{Predictors of BP/CR}

WHO currently recommends at least eight contacts with a health care provider during the antenatal period in order to improve maternal and perinatal outcomes [35]. Women who reported $\geq 4$ antenatal visits were more likely to be birth prepared as compared with women with fewer visits, in agreement with studies in Southern Ethiopia, Kenya, Uganda and Ghana [10, 20, 33].
Similar to our findings, women with salaried work were 3.5 times more likely to be prepared for birth as compared with unemployed women in a study from Kenya [26]. Employed women are generally known to have more autonomy to make decisions concerning their health, thereby preventing delays in seeking healthcare [36-38]. In contrast, studies in South West Ethiopia and northern Ghana found no association between occupation and BP/CR $[15,39]$. This could be attributed to the fact that most women in the Kassena Nankana District of Ghana were housewives and the Ethiopian government's free provision of ambulance and other maternal and child health services [15, 39].

Maternity related community groups are shown to be generally supportive during pregnancy [40]. In India reported youth groups are undertaking activities to increase sensitization of maternal health problems and this improved maternal health outcomes [41]. Women who belonged to maternal health promoting clubs or groups during the antenatal period were found to be three times more likely to be birth prepared as compared with women without such clubs or groups. In our study, only $41 \%$ of the mothers belonged to such groups. Pregnant women may not always be aware of the supportive role played by the community in promoting BP/CR. This assertion is buttressed by a study in Nigeria where many women were not aware of existing community support mechanisms or programmes [42].

\section{Strengths and limitations}

The criteria for $\mathrm{BP} / \mathrm{CR}$ in this study were adapted from the MCHR 2018 book, which is the standard manual for focused antenatal care in all health institutions in Ghana. Therefore, the level of BP/CR could be presumed to be close to what actually exists amongst the study population. Additionally, the study was adequately powered with a large sample size of 300 participants to enable generalizability of the results. Furthermore, inclusion criteria for this study were limited to mothers who were within six weeks after birth to minimize recall bias.

High levels of BP/CR among the study population could be due to the fact that this was a health facility-based study and most women interviewed had been regular ANC attendants during their index pregnancy. Another limitation of the study was that most women had higher levels of education and this could have influenced the level of $\mathrm{BP} / \mathrm{CR}$, although education was not found to be a predictor of BP/CR. However, this educational level is more reflective of the level among women attending PNC in these urban facilities and not only those who decided to participate in the study. 


\section{Conclusion}

The level of BP/CR among study participants was generally high. Strong determinants of BP/CR included having $\geq 4$ antenatal clinic visits, maternal employment and participation in maternal health promoting clubs or groups during the antenatal period.

Although BP/CR is one of the strategies employed by the Safe Motherhood Initiative to combat maternal mortality, there are no clearly defined criteria globally as to what it should entail [11]. Key definitions concerning $\mathrm{BP} / \mathrm{CR}$ have not been agreed upon by experts, although various guidelines exist, and this makes assessment of interventions difficult [10]. Our study adds to the current literature on $\mathrm{BP} / \mathrm{CR}$ and may guide future research and development of policy regarding BP/CR criteria that can be used to routinely assess $\mathrm{BP} / \mathrm{CR}$.

\section{Supplementary information}

Supplementary information accompanies this paper at https://doi.org/10. 1186/s12884-020-03263-6.

Additional file 1: Appendix I. Questionnaire.

\section{Abbreviations}

ANC: Antenatal Clinic; aOR: Adjusted Odds Ratio; BP/CR: Birth Preparedness and Complication Readiness; Cl: Confidence Interval; DHS: Demographic and Health Survey; EDD: Expected Date of Delivery; GHS: Ghana Health Service; JHPIEGO: Johns Hopkins Program for International Education in Gynaecology and Obstetrics; MCHR: Maternal and Child Health Records; PCA: Principal Component Analysis; PNC: Postnatal clinic; SDG: Sustainable Development Goal; WHO: World Health Organization

\section{Acknowledgements}

We are grateful to the Ghana Health Service and the heads of facility of both study sites for their cooperation.

\section{Authors' contributions}

CK and PA designed the study. CK and KA conducted data collection, data analysis, interpretation and wrote the first manuscript. BJM and AAA participated immensely in preparing the draft manuscript for publication. All authors have read and approved the manuscript.

\section{Funding}

The authors did not receive funding for this study.

\section{Availability of data and materials}

The datasets obtained from the current study will be made available by the corresponding author when requested.

\section{Ethics approval and consent to participate}

Ethical clearance was obtained from the Ghana Health Service Ethics Review Committee (ID No. GHS-ERC 191022) and permission sought from the study sites. A written consent was subsequently obtained from the participants after the study was explained in simple terms and in details with anonymity of their responses assured.

\section{Consent for publication}

Not applicable.

\section{Competing interests}

The authors declare they have no competing interests.

\section{Author details}

'Department of Health Policy, Planning and Management, School of Public Health, College of Health Sciences, University of Ghana - Legon, P.O. Box LG 13, University of Ghana, Legon, Ghana. ${ }^{2}$ Department of Nutrition Sciences, Centre for Family Intervention Science, College of Nursing and Health Professions, Drexel University, 1601 Cherry Street. Suite 383, Philadelphia, PA 19102, USA. ${ }^{3}$ Ministry of Education, National Inspectorate Board, Private Mail Bag 18, Ministries Post Office, Ameda Street, Yooyi Ln, Accra, Ghana.

Received: 6 February 2020 Accepted: 18 September 2020

Published online: 25 September 2020

\section{References}

1. Ghana Statistical Service (GSS), Ghana Health Service (GHS), ICF. Ghana maternal health survey 2017. Accra: GSS, GHS, and ICF; 2018.

2. Azeze GA, Mokonnon TM, Kercho MW. Birth preparedness and complication readiness practice and influencing factors among women in Sodo town, Wolaita zone, southern Ethiopia, 2018; community based cross-sectional study. Reprod Health. 2019 Dec 1;16(1):39.

3. Ghana Health Service (GHS). Ghana Health Service 2016 Annual Report; 2017. p. 1-129.

4. Nawal D, Goli S. Birth preparedness and its effect on place of delivery and post-natal check-ups in Nepal. PloS one. 2013;8(5):e60957.

5. Ghana Statistical Service (GSS), Ghana Health Service (GHS), and ICF International. Ghana demographic and health survey 2014. Rockville: GSS, GHS, and ICF International; 2015.

6. World Health Organization. Birth and emergency preparedness in antenatal care. 2006. [cited 20 April 2020] Available from: http://www.who.int/ reproductivehealth/publications/maternal_perinatal_health/emergency_ preparedness_antenatal_care.pdf.

7. Baffour-Awuah A, Mwini-Nyaledzigbor PP, Richter S. Enhancing focused antenatal care in Ghana: an exploration into perceptions of practicing midwives. Int J Africa Nurs Sci. 2015;2:59-64.

8. Lincetto O, Mothebesoane-Anoh S, Gomez P, Munjanja S. Antenatal Care. In: Lawn J, Kerber K, editors. Opportunities for Africa's newborns: practical data, policy and programmatic support for newborn care in Africa. Geneva: World Health Organization; 2006. p. 51-62.

9. Pervin J, Nu TU, Rahman AMQ, Rahman M, Uddin B, Razzaque A, et al. Level and determinants of birth preparedness and complication readiness among pregnant women : a cross sectional study in a rural area in Bangladesh. PLoS One. 2018;13(12):1-14.

10. Miltenburg AS, Roggeveen Y, van Roosmalen J, Smith H. Factors influencing implementation of interventions to promote birth preparedness and complication readiness. BMC Pregnancy Childbirth. 2017;17(1):270.

11. JHPIEGO/Maternal and Neonatal Health Program. Monitoring Birth Preparedness and Complication Readiness: Tools and Indicators for Maternal and Newborn Health. Bloomberg school of public health. 2004

12. Mcpherson RA, Khadka N, Moore JM, Sharma M. Are birth-preparedness Programmes effective ? Results from a field trial in Siraha District, Nepal. J Heal Popul Nutr. 2006:24(4):479-88.

13. Kalisa $R$, Smeele $P$, van Elteren $M$, van den Akker $T$, van Roosmalen J. Facilitators and barriers to birth preparedness and complication readiness in rural Rwanda among community health workers and community members: a qualitative study. Matern Heal Neonatol Perinatol. 2018;4(1):1-7.

14. Affipunguh PK, Laar AS. Assessment of knowledge and practice towards birth preparedness and complication readiness among women in northern Ghana: a cross-sectional study. Int J Sci Reports. 2016;2(6):121-9.

15. Kunganab-Lem RB, Dogudugu R, Kanton L. Birth preparedness and complication readiness: a study of postpartum women in a Rural District of Ghana. Sci Acad Publ. 2014;4(6):225-33.

16. Siakwa M, Suglo S. Knowledge and practice on birth preparedness among expectant mothers seeking antenatal care at the tamale teaching hospital, Ghana. Int J Res Med Heal Sci. 2016:8:13-24.

17. Ministry of Health, Ghana Health Service, (JICA) JICA. Maternal and Child Health Record Book. 1.1. Ministry of Health, Ghana Health Service, editors. Ministry of Health; Ghana Health Service; 2018. p. 18-9.

18. JICA. Human Security and Quality Growth SCENE 1: Health / Maternal and Child Health handbooks (MCH handbooks) providing the strength to live. JICA. 2019. [cited 21 April 2020] Available from: https://www.jica.go.jp/ english/publications/j-world/1901_02.html. 
19. World Health Organization. DANGER SIGNS IN PREGNANCY. In: Counselling for Maternal and Newborn Health Care: A Handbook for Building Skills. Geneva: WHO Press; 2013.

20. Metrics for Management. Equity Tool. Metrics for Management. 2014 [cited 3 April 2019]. Available from: http://www.equitytool.org/ghana/.

21. Sabageh AO, Adeoye OA, Adeomi AA, Sabageh D, Adejimi AA. Birth preparedness and complication readiness among pregnant women in Osogbo Metropolis, Southwest Nigeria. Pan Afr Med J. 2017;27:74.

22. Kamineni V, Murki A, Kota V. Birth preparedness and complication readiness in pregnant women attending urban tertiary care hospital. J Fam Med Prim Care. 2017:6(2):297.

23. Kumadi SRE. Birth Preparednss among Expectant Teenagers in Ledzorkuku Krowor Municipal Assembly. [Master's thesis on internet] Legon, University of Ghana 2015.[cited 19 Dec 2019] Available from: ugspace.ug.edu.gh.

24. Begashaw B, Tesfaye $Y$, Zelalem E, Ubong U, Kumalo A. Assessment of birth preparedness and complication readiness among pregnant mothers attending ante Natal Care Service in Mizan-Tepi University Teaching Hospital, south West Ethiopia. Clinics Mother Child Health. 2017;14(257):2.

25. Agarwal S, Sethi V, Srivastava K, Jha PK, Baqui AH. Birth preparedness and complication readiness among slum women in Indore city, India. J Heal Popul Nutr. 2010:28(4):383-91.

26. Gitonga E, Keraka M, Mwaniki P. Birth preparedness among women in Tharaka Nithi County, Kenya. Afr J Midwifery Womens Health. 2015;9(4): 153-7.

27. Jatoe JBD, Al-Hassan R, Adekunle B. Why northern Ghana lags behind in Ghana's growth and poverty reduction success. AERC Africa; 2018. p. 1-4. [cited 26 Dec 2018]. Available from: https://aercafrica.org/wp-content/ uploads/2018/07/GPB_08-Jatoe_et_al.pdf.

28. Sumankuuro J, Crockett J, Wang S. Factors influencing knowledge and practice of birth preparedness and complication readiness in sub-saharan Africa: a narrative review of cross-sectional studies. Int J Community Med Public Health. 2016;3(12):3297-307.

29. Asamoah-Akuoko L, Hassall OW, Bates I, Ullum H. Blood donors' perceptions, motivators and deterrents in sub-Saharan Africa - a scoping review of evidence. Br J Haematol. 2017;177(6):864-77.

30. SPRING, Ghana Health Service. Ghana: Landscape Analysis of Anemia and Anemia Programming. Arlington: Strengthening partnerships, results, and innovations in nutrition globally (SPRING) project; 2016.

31. Schantz-Dunn J. The use of blood in obstetrics and gynecology in the developing world. Rev Obstet Gynecol. 2011;4(2):86-91.

32. Hailu M, Gebremariam A, Alemseged F. Knowledge about obstetric danger signs among pregnant women in Aleta Wondo District, Sidama Zone, Southern Ethiopia. Ethiop J Health Sci. 2010;20(1):25-32.

33. Bintabara D, Mpembeni RNM, Mohamed AA. Knowledge of obstetric danger signs among recently-delivered women in Chamwino district, Tanzania: a cross-sectional study. BMC Pregnancy Childbirth. 2017;17(1):1-10.

34. Teng SP, Zuo TC, Jummaat FB, Keng SL. Knowledge of pregnancy danger signs and associated factors among Malaysian mothers. Br J Midwifery. 2015:23(11):800-6.

35. WHO. WHO recommendation on antenatal care contact schedules. The WHO Reproductive Health Library. 2018 [cited 26 Sep 2019]. Available from: https://extranet.who.int/rhl/topics/improving-health-system-performance/ who-recommendation-antenatal-care-contact-schedules.

36. Cheptum J, Omoni G, Mirie W. Factors Affecting Birth Preparedness among Pregnant Women Attending Public Antenatal Clinics in Migori County, Kenya. Kenya Biomed J Sci \&Tech Res. 2018;3(4):3409-15.

37. Singh K, Bloom S. Influence of Women's Empowerment on Maternal Health and Maternal Health Care Utilization: A Regional Look at Africa. 2007. (PAA2011; vol. 52). Report No.: 110362.

38. Koustuv D, Shabnam J, Andrews-Chavez J, Mårtensson LB, Toomas T. Economic empowerment of women and utilization of maternal delivery Care in Bangladesh. Int J Prev Med. 2012;3(9):628-36.

39. Begashaw B, Tesfaye $Y$, Kumalo A. Assessment of birth preparedness and complication readiness among pregnant mothers attending ante Natal Care Service in Mizan-Tepi University Teaching Hospital, South West Ethiopia. ResearchGate. 2017;14(1):1-7.

40. Ibadin SH, Adam VY, Adeleye OA, Okojie OH. Birth preparedness and complication readiness among pregnant women admitted in a rural hospital in Nigeria. African J Obstet Gynaecol. 2016;22(2):47-51.

41. Miltenburg AS, van der Eem L, Nyanza EC, van Pelt S, Ndaki P, Basinda N, Sundby J. Antenatal care and opportunities for quality improvement of service provision in resource limited settings: a mixed methods study. PLoS One. 2017;12(12):e0188279.

42. Ekabua JE, Ekabua KJ, Odusolu P, Agan TU, Iklaki CU, Etokidem AJ. Awareness of birth preparedness and complication readiness in southeastern Nigeria. ISRN Obstet Gynecol. 2011;2011:6.

\section{Publisher's Note}

Springer Nature remains neutral with regard to jurisdictional claims in published maps and institutional affiliations.
Ready to submit your research? Choose BMC and benefit from:

- fast, convenient online submission

- thorough peer review by experienced researchers in your field

- rapid publication on acceptance

- support for research data, including large and complex data types

- gold Open Access which fosters wider collaboration and increased citations

- maximum visibility for your research: over $100 \mathrm{M}$ website views per year

At $\mathrm{BMC}$, research is always in progress.

Learn more biomedcentral.com/submissions 